\title{
Characterization and discrimination of evolving mineral and plant oil slicks based on L-band synthetic aperture radar (SAR)
}

\author{
Cathleen E. Jones ${ }^{* a}$, Martine M. Espeseth ${ }^{\mathrm{b}}$, Benjamin Holt ${ }^{\mathrm{a}}$, Camilla Brekke ${ }^{\mathrm{b}}$, Stine Skrunes ${ }^{\mathrm{b}}$ \\ ${ }^{a}$ Jet Propulsion Laboratory, California Institute of Technology, 4800 Oak Grove Dr., Pasadena, CA, \\ USA 91109; ${ }^{b}$ UiT, The Arctic University of Norway, Tromsø, Norway
}

\begin{abstract}
Evolution of the damping ratio for Bragg wavenumbers in the range $32-43 \mathrm{rad} / \mathrm{m}$ is evaluated for oil slicks of different composition released in the open ocean and allowed to develop naturally. The study uses quad-polarimetric L-band airborne synthetic aperture radar data acquired over three mineral oil emulsion releases of different, known oil-to-water ratio, and a near-coincident release of 2-ethylhexyl oleate that served as a biogenic look-alike. The experiment occurred during the 2015 Norwegian oil-on-water exercise in the North Sea during a period of relatively high winds $(\sim 12 \mathrm{~m} / \mathrm{s})$. NASA's Uninhabited Aerial Vehicle Synthetic Aperture Radar (UAVSAR) was used to repeatedly image the slicks over a period of eight hours, capturing the slicks' early development and providing a time series from which to track the evolution of the slicks' size, position, and radiometric characteristics. Particular emphasis is given in this analysis to identification of zones of higher damping ratio within the slicks (zoning) as potential indicators of thicker oil, and to comparison of the evolution of emulsion and plant oil damping ratios. It was found that all mineral oil slicks initially exhibited zoning apparent in VV, HH, and HV intensities, and that the areas of higher damping ratio persisted the longest for the highest oil content emulsion ( $80 \%$ oil by volume). In contrast, zoning was not unambiguously evident for plant oil at any time from 44 minutes to 8.5 hours after release.
\end{abstract}

Keywords: oil slick, damping ratio, weathering, synthetic aperture radar (SAR), PolSAR, UAVSAR, NORSE2015

\section{OVERVIEW}

Petroleum oil spills are potentially high impact disasters and require robust, active spill response to protect communities, the ecosystem, and the energy supply. Use of remote sensing to direct response can substantially increase spatial coverage while simultaneously decreasing response time, and enable observation in remote and cloudy areas. These capabilities are becoming more important as the Arctic is opened to oil transport and extraction. Although radar has long been used for mapping the spatial extent of oil slicks ${ }^{1-3}$, the large release volumes of the Deepwater Horizon (DWH) spill in 2010 were studied extensively to show synthetic aperture radar (SAR) capable of characterizing properties needed to direct responders to recoverable oil, namely volumetric oil fraction ${ }^{4,5}$ or thickness ${ }^{6}$. Although the nascent studies based on the DWH spill provided some evidence of SAR's suitability for directing emergency responders to the highest impact areas, robust verification of the results was not obtained during the chaos of the spill response to that major disaster.

To address this deficiency, in June 2015 a new study was undertaken in which emulsions of known quantity and waterto-oil ratio, along with a look-alike slick of plant oil, were released in the open ocean. Held during the 2015 Norwegian oil-on-water spill exercise in the North Sea (OPV2015), the NORSE2015 (NOrwegian Radar oil Spill Experiment) involved controlled release of plant oil and mineral emulsions of three different oil-to-water ratios; near-coincident imaging of the slicks with TerraSAR-X, Radarsat-2, and RISAT-1 SAR instruments ${ }^{7,8}$; and tracking changes in the slicks on the sea surface with the NASA L-band Uninhabited Aerial Vehicle Synthetic Aperture Radar (UAVSAR), an airborne instrument, over a period of approximately eight hours following release.

The time series of UAVSAR images is unique in providing high resolution (1.7 $\mathrm{m} \mathrm{x} 1 \mathrm{~m}$ single-look), low noise, quadpolarization data for tracking the evolution of the slicks' size, position, and radiometric characteristics over a sufficiently long period for significant transport and weathering to occur. The results of a study using the slick centroid locations to refine an oil transport model, comparing entrainment, vertical mixing, and horizontal transport of the high oil emulsion to the plant oil simulant, has been previously reported ${ }^{9}$. Here we focus on the evolution of the radiometric properties of

*Cathleen.e.jones@jpl.nasa.gov; phone 1-818-393-1048; fax 1-818-393-5184

SAR Image Analysis, Modeling, and Techniques XVI, edited by Claudia Notarnicola, Simonetta Paloscia, Nazzareno Pierdicca, Edward Mitchard, Proc. of SPIE Vol. 10003, 100030K · (c) 2016 SPIE CCC code: $0277-786 X / 16 / \$ 18 \cdot$ doi: $10.1117 / 12.2241266$ 
the different slicks, which are indicative of weathering and loss. Many different radiometric features, including a number of polarization-dependent features, have been suggested and/or used previously for slick detection (see, e.g., Skrunes et al. $^{10}$ and references therein), but for this work we focus on the long-studied damping ratio ${ }^{3,5,11}$, defined as

$$
R_{T R}=\sigma_{\text {water }} / \sigma_{\text {slick}}
$$

where $\sigma_{o}$ is the normalized radar cross section, and TR is an indicator of the polarization of the transmit (T) and receive (R) channels of the radar, which for UAVSAR can be either horizontal $(\mathrm{H})$ or vertical (V) linear polarization. Radar backscatter from the sea surface is sensitive to the component of the ocean wave spectrum at the Bragg wavenumber, ${ }^{12}$

$$
k_{b}=4 \pi \sin \Theta_{\text {inc }} / \lambda_{\text {radar }},
$$

where $\lambda_{\text {radar }}$ is the radar wavelength and $\Theta_{\text {inc }}$ is the local incidence angle.

The damping ratio for mineral oil slicks has been observed to increase with increasing wavenumber ${ }^{11}$, in which case it would be larger for the shorter wavelength radars (X-band > C-band > L-band), and to increase with increasing incidence angle for a given radar frequency. Minchew et al. ${ }^{4}$ reported that the UAVSAR-derived damping ratios measured across the main slick of the DWH spill generally followed these trends for all polarization channels at incidence angles for which the measured backscatter was at least $6 \mathrm{~dB}$ above the instrument noise floor. Slightly less damping was observed in the HH channel than in the VV or HV channels, along with a possible upwind/downwind difference for which the interpretation was complicated by the fact that the two acquired swaths covered different parts of the extensive, thick, and highly weathered DWH slick. ${ }^{4}$ The damping ratio of a mineral oil slick has been observed to decrease with increasing wind speed due to the background of wind-generated waves, and in addition due to the fact that at high wind speeds, in the range $10-14 \mathrm{~m} / \mathrm{s}$, breaking waves will entrain the oil, breaking up the slicks. ${ }^{13}$ Biogenic slicks are less likely to be present under wind conditions above $7-10 \mathrm{~m} / \mathrm{s}$ because of entrainment. ${ }^{13}$ Wisman et al. ${ }^{14}$ found the damping ratio to increase with oil thickness in a mineral oil slick, which is consistent with variability seen with UAVSAR during the Deepwater Horizon spill. ${ }^{15}$

In the work reported here, the high spatial resolution of the UAVSAR data is used to measure variations in the damping ratio within the slicks (zoning) to determine whether areas of possible thicker oil are evident within the different slicks and for how long the zoning persists. In addition, the polarization dependence and the temporal evolution of the damping ratios are reported and compared for the different types of oil slicks.

\section{EXPERIMENT DESCRIPTION}

The experiment occurred on 10 June 2015 at the Frigg Field site in the North Sea off the coast of Norway $\left(59^{\circ} 59^{\prime} \mathrm{N}\right.$, $\left.2^{\circ} 27^{\prime} \mathrm{E}\right)$, during the oil-on-water exercise held by the Norwegian Clean Seas Association for Operating Companies (NOFO). Three oil emulsions based upon Troll and Oseberg crude oils were prepared prior to the exercise with oil-towater volumetric ratios of 40:60, 60:40, and 80:20. Four releases occurred $\sim 1 \mathrm{~km}$ apart (Table 1), starting with the 2ethylhexyl oleate, a monoalkyl ester of an oleic acid (Radiagreen EBO), which is a plant oil, released furthest to the south at 4:48 UTC, then the mineral oil emulsion releases in order of increasing oil content to the north of the plant oil release. Release volumes were $0.5 \mathrm{~m}^{3}$ ( 3 barrels) for each of the emulsions and $0.2 \mathrm{~m}^{3}$ for the Radiagreen EBO, sufficient to develop into slicks $0.25-1 \mathrm{~km}^{2}$ in areal extent. ${ }^{9}$ The emulsions, two of which are shown in Figure 1 , were red-brown in color upon release, which is the color of stable and meta-stable water-in-oil emulsions. ${ }^{16}$ The volume of released material was small enough that slick thickness was on average $1 \mathrm{um}$ (plant oil) and $0.04 \mathrm{~mm}$ (emulsions) at 05:48 UTC, assuming that the slick was a uniform thickness and that no material had yet been entrained. This sets an upper limit for the average thickness of the slicks on the surface at later times. Wind speed that day was relatively high and variable in the range $9-12 \mathrm{~m} / \mathrm{s}$, but generally between $10-12 \mathrm{~m} / \mathrm{s}$ for the hours of observation (Table 2). More details about the experiment, environmental conditions, and slick extent are available in previous publications ${ }^{7,8,9}$ and a companion paper in this volume. ${ }^{17}$

UAVSAR is a left-side-looking L-band SAR ${ }^{18}$ operating at $1.257 \mathrm{GHz}$ center frequency and with $80 \mathrm{MHz}$ bandwidth. A series of 22 UAVSAR images were acquired on 10 June 2015 between 05:33 and 13:22 UTC, and we report evolution of the damping ratio based upon a representative sample of the images selected to show the change in damping ratio, which was most rapid immediately following release. The UAVSAR data was collected during two flights because of the need to refuel, so there is a gap in the imaging that occurs between $\sim 4-7$ hours following release, with slightly different times for each slick because of their different release times. 

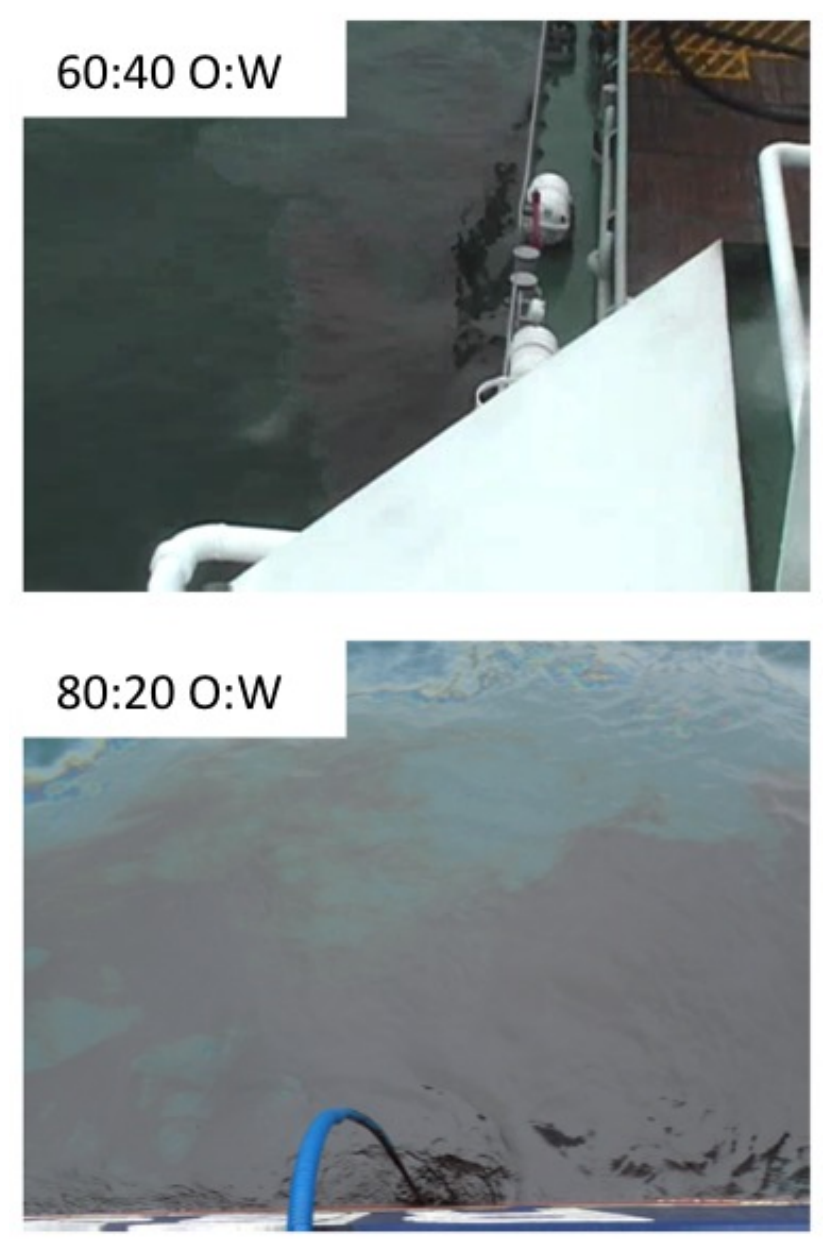

Figure 1. Photographs of the mineral oil emulsions with 60:40 and 80:20 oil-to-water volumetric ratios (O:W) upon their release. The emulsions have the red-brown color observed in stable and meso-stable water-in-oil emulsions. ${ }^{16}$ [Photo credit: Norwegian Clean Seas Association for Operating Companies (top) and Øyvind Breivik (bottom)]

Table 1. Information about the materials released during the NORSE2015 experiment. The oil-to-water volumetric ratio $(\mathrm{O}: \mathrm{W})$ is given for each emulsion.

\begin{tabular}{|c|c|c|c|c|}
\hline Substance & Constituent(s) & $\begin{array}{l}\text { Release start } \\
\text { time/location }\end{array}$ & $\begin{array}{c}\text { Release end } \\
\text { time/location }\end{array}$ & Vol. \\
\hline Plant Oil & $\begin{array}{c}\text { Radiagreen EBO } \\
\text { (2-ethylhexyl oleate) }\end{array}$ & $\begin{array}{c}04: 48 \mathrm{UTC} \\
60^{\circ} 1.653^{\prime} \mathrm{N}, \\
2^{\circ} 23.022^{\prime} \mathrm{E}\end{array}$ & $\begin{array}{c}\text { Not } \\
\text { Available }\end{array}$ & $0.2 \mathrm{~m}^{3}$ \\
\hline $\begin{array}{c}\text { Mineral Oil } \\
\text { Emulsion } \\
(40: 60)\end{array}$ & $\begin{array}{c}300 \text { L water } \\
100 \text { L Troll } \\
100 \text { L Oseberg } \\
0.2 \text { L One-Mul }\end{array}$ & $\begin{array}{l}04: 59 \text { UTC } \\
60^{\circ} 2.141^{\prime} \mathrm{N}, \\
2^{\circ} 23.226^{\prime} \mathrm{E}\end{array}$ & $\begin{array}{c}05: 06 \mathrm{UTC} \\
60^{\circ} 2.243^{\prime} \mathrm{N}, \\
2^{\circ} 23.376^{\prime} \mathrm{E}\end{array}$ & $0.5 \mathrm{~m}^{3}$ \\
\hline $\begin{array}{c}\text { Mineral Oil } \\
\text { Emulsion } \\
(60: 40)\end{array}$ & $\begin{array}{c}200 \text { L water } \\
150 \text { L Troll } \\
150 \text { L Oseberg } \\
0.2 \text { L One-Mul }\end{array}$ & $\begin{array}{l}05: 15 \text { UTC } \\
60^{\circ} 2.602^{\prime} \mathrm{N}, \\
2^{\circ} 23.348^{\prime} \mathrm{E}\end{array}$ & $\begin{array}{l}05: 20 \text { UTC } \\
60^{\circ} 2.706^{\prime} \mathrm{N}, \\
2^{\circ} 23.314^{\prime} \mathrm{E}\end{array}$ & $0.5 \mathrm{~m}^{3}$ \\
\hline $\begin{array}{c}\text { Mineral Oil } \\
\text { Emulsion } \\
(80: 20)\end{array}$ & $\begin{array}{c}100 \text { L water } \\
200 \text { L Troll } \\
200 \text { L Oseberg } \\
0.2 \text { L One-Mul }\end{array}$ & $\begin{array}{l}05: 30 \text { UTC } \\
60^{\circ} 3.099^{\prime} \mathrm{N}, \\
2^{\circ} 23.447^{\prime} \mathrm{E}\end{array}$ & $\begin{array}{c}05: 35 \mathrm{UTC} \\
60^{\circ} 2.978^{\prime} \mathrm{N}, \\
2^{\circ} 23.334^{\prime} \mathrm{E}\end{array}$ & $0.5 \mathrm{~m}^{3}$ \\
\hline
\end{tabular}


The analysis used standard geocoded multilooked normalized radar cross section products posted at $5.5 \mathrm{~m}$ pixel spacing [http://uavsar.jpl.nasa.gov/science/documents/polsar-format.html]. The data was further smoothed using a $5 \times 5$ sliding boxcar filter. The instrument has a high signal-to-noise ratio, with noise equivalent sigma zero (NESZ) between -48 and $-40 \mathrm{~dB}\left(-45 \mathrm{~dB}\right.$ typical) for the range of incidence angles at which the slicks were imaged. ${ }^{19}$ The backscattered signals for all polarization channels and for all slicks exceeded the noise floor by at least $6 \mathrm{~dB}$ throughout the NORSE2015 experiment. $^{7}$

Table 2. Wind speed, wave height, and sea surface temperature on 10 June 2015 at the NORSE2015 site.

\begin{tabular}{|c|c|c|c|}
\hline $\begin{array}{c}\text { Time } \\
{[\mathbf{U T C}]}\end{array}$ & $\begin{array}{c}\text { Wind Speed }[\mathbf{m} / \mathbf{s}] \\
\left({ }^{\circ} \mathbf{N}(\mathbf{f r o m})\right)\end{array}$ & $\begin{array}{c}\text { Wave height } \\
{[\mathbf{m}]}\end{array}$ & $\begin{array}{c}\text { Air Temperature at } \\
\text { Sea Surface }\left[{ }^{\circ} \mathbf{C}\right]\end{array}$ \\
\hline $04: 30$ & 12 & 2.5 & $10^{\circ}$ \\
\hline $04: 50$ & 11 & 2.5 & $9^{\circ}$ \\
\hline $05: 34$ & $9\left(248^{\circ}\right)$ & & $10.2^{\circ}$ \\
\hline $06: 18$ & $12\left(260^{\circ}\right)$ & & \\
\hline $06: 52$ & & & $9^{\circ}$ \\
\hline $07: 15$ & $12\left(263^{\circ}\right)$ & & $11^{\circ}$ \\
\hline $07: 55$ & $10\left(260^{\circ}\right)$ & & $10.2^{\circ}$ \\
\hline $08: 00$ & 10 & 2 & $10^{\circ}$ \\
\hline $09: 00$ & 9 & 2.5 & $10^{\circ}$ \\
\hline $10: 26$ & $11\left(258^{\circ}\right)$ & & $9^{\circ}$ \\
\hline $11: 25$ & & & $10^{\circ}$ \\
\hline $13: 00$ & 12 & 2.5 & $8^{\circ}$ \\
\hline $14: 38$ & & & \\
\hline $15: 30$ & $10\left(264^{\circ}\right)$ & & \\
\hline $17: 00$ & 10 & 2.5 & \\
\hline $17: 12$ & & & \\
\hline $21: 00$ & 12 & & \\
\hline
\end{tabular}

\section{RESULTS \& DISCUSSION}

\subsection{Temporal evolution of the mineral oil emulsions' damping ratios}

Figures 2, 3, and 4 show the temporal evolution of the damping ratio for the slicks with 80:20 oil emulsion, 60:40 oil emulsion, and 40:60 oil emulsion, respectively, starting with the earliest image of the slick and ending with the final image of the series. The same color scale is used for all figures. The slicks were masked from the clean sea manually with a sufficiently large mask to capture the margins. The clean sea values are obtained from an adjacent area without slicks or bright reflectors and with the same incidence angles so as to match the Bragg wavenumber. Values calculated from the VV, HH, and $\mathrm{HV}$ intensities are all shown for comparison purposes. The measured damping ratios are similar for all three polarization channels. The particular channel showing the highest contrast within the slicks is not consistent for a given emulsion or a given time. The exception occurs in one scene, at which time there is an increase in the VV damping ratio, which is shown in the figures at time since release, $\Delta \mathrm{T}_{\mathrm{r}}=2: 00(80: 20), 2: 15(60: 40)$, and 2:31 (40:60). Unlike at the other time steps, the VV damping ratio is different than the values for the other two polarization channels, indicating that some sea or wind condition altered the damping ratio, rather than a change in the material properties of the slicks. Given this variability, no conclusion on the relative merits of the different polarization channels in differentiating areas of thicker oil within a slick can be drawn.

Initially, all slicks, regardless of oil volumetric fraction, show zoning, i.e., areas of higher damping in the interior of the slick, and they all have similar maximum damping, 4.5-5.5 in value. The 40:60 oil emulsion (Figure 4) shows the lowest damping of the three emulsion slicks at $\sim 30$ minutes following release, and the damping ratio rapidly decreases in the next hour to the point where the slick is patchily differentiated from the clean sea, and becomes nearly indistinguishable by seven hours following release. The downwind side of the slick (east) is the first to disappear, and the radar-detected portion of the slick, which initially spread in the downwind direction, significantly decreased in area by 7 hours following release. The 60:40 oil emulsion (Figure 3) maintains a high damping ratio in interior zones at $\sim 30$ minutes following release, but the contrast within the zones steadily decreases over the next hour. The slick is still clearly visible with some apparent zoning at $\sim 3$ hours following release, but by $\sim 7$ hours following release no zoning is apparent. The slick disappears from the downwind side first, and the radar-detectible area starts to shrink between $\sim 6.75$ 
and 8 hours following release. The highest damping ratios measured were for the 60:40 oil emulsion, not the 80:20 oil emulsion (Figure 2). The 80:20 oil emulsion's damping ratio followed the same pattern as the 60:40 oil emulsion initially, but maintained apparent zoning and was well delineated from the clear water for much longer, with the detected area beginning to decrease at 8 hours following release when the last UAVSAR image was acquired.

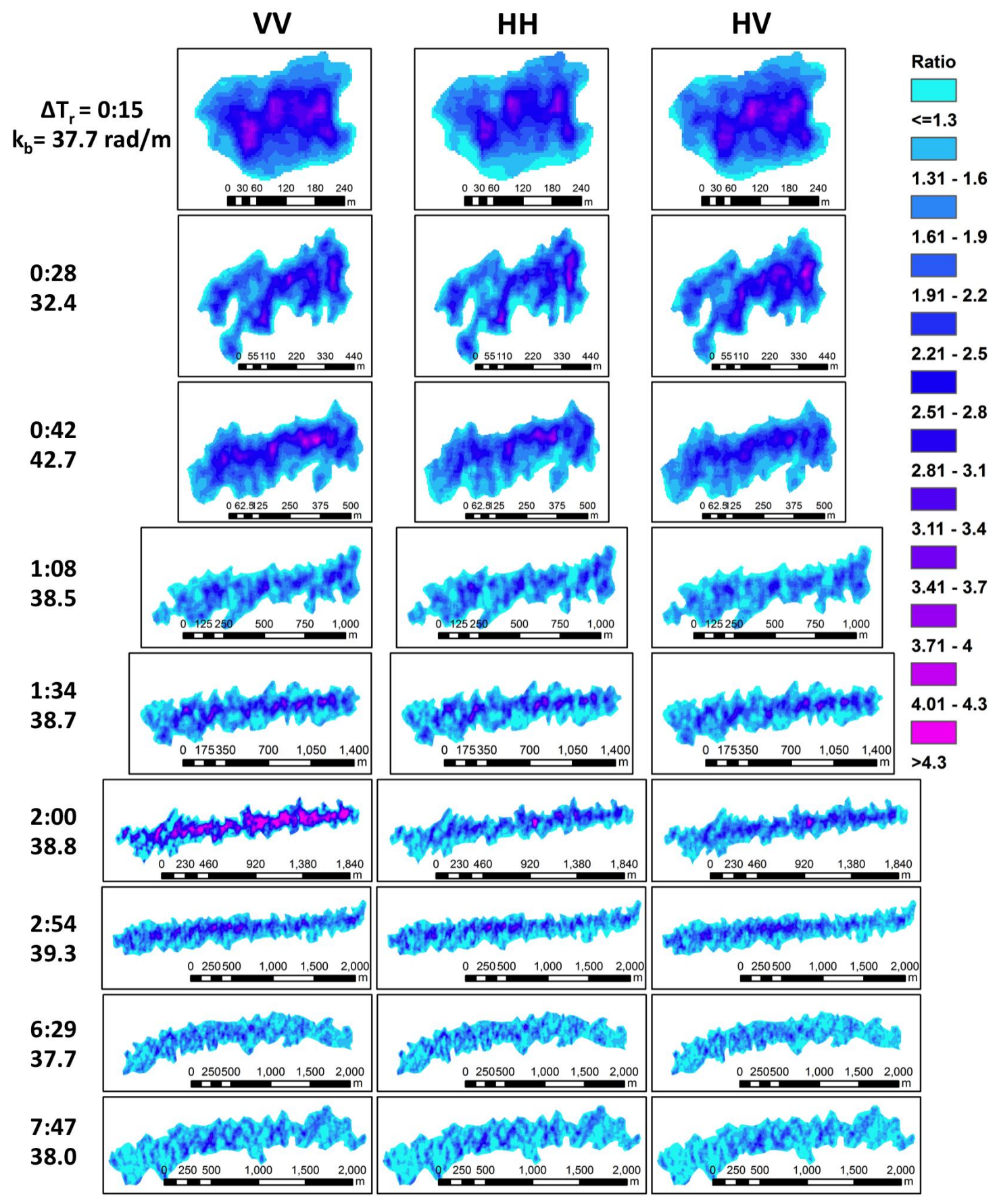

Figure 2. Evolution of the damping ratio for the 80:20 oil-to-water fraction emulsion from 15 minutes following release $\left(\Delta \mathrm{T}_{\mathrm{r}}=0: 15\right)$ to 7 hours, 47 minutes following release $\left(\Delta \mathrm{T}_{\mathrm{r}}=7: 47\right)$. The masks are sized to capture the margins at the interface with clean water and the scale bars show how the slick extent changed with time. The damping ratio is calculated from the VV (left), HH (center) and HV (right). The Bragg wavenumber $\left(\mathrm{k}_{\mathrm{b}}\right)$ at the slick centroid is indicated for each time step. Note the change in scale for different time steps. 


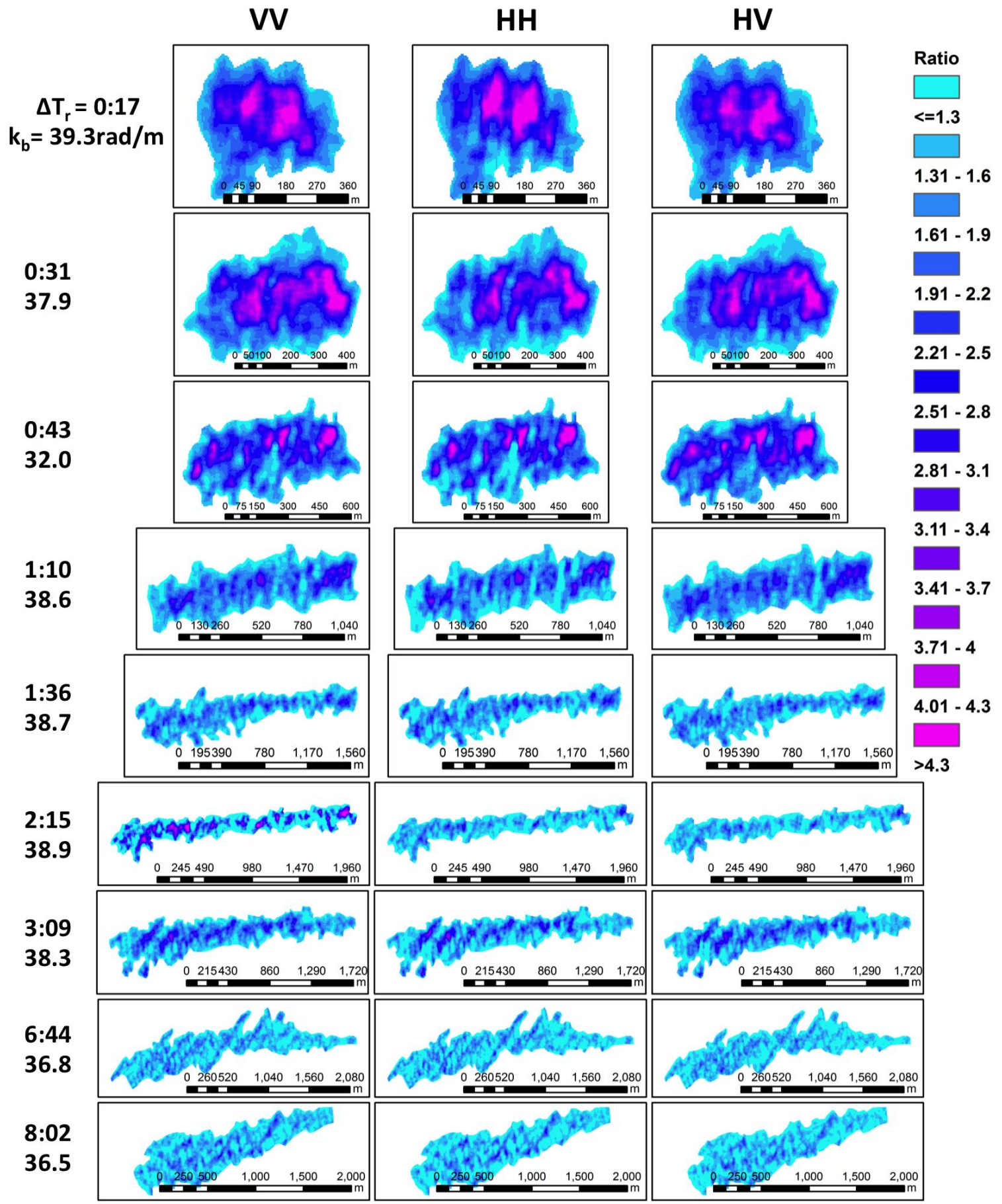

Figure 3. Evolution of the damping ratio for the 60:40 oil-to-water fraction emulsion from 17 minutes following release $\left(\Delta \mathrm{T}_{\mathrm{r}}=0: 17\right)$ to 8 hours, 2 minutes following release $\left(\Delta \mathrm{T}_{\mathrm{r}}=8: 02\right)$. The masks are sized to capture the margins at the interface with clean water and the scale bars show how the slick extent changed with time. The damping ratio is calculated from the VV (left), HH (center) and HV (right) intensities. The Bragg wavenumber $\left(\mathrm{k}_{\mathrm{b}}\right)$ at the slick centroid is indicated for each time step. Note the change in scale for different time steps. 


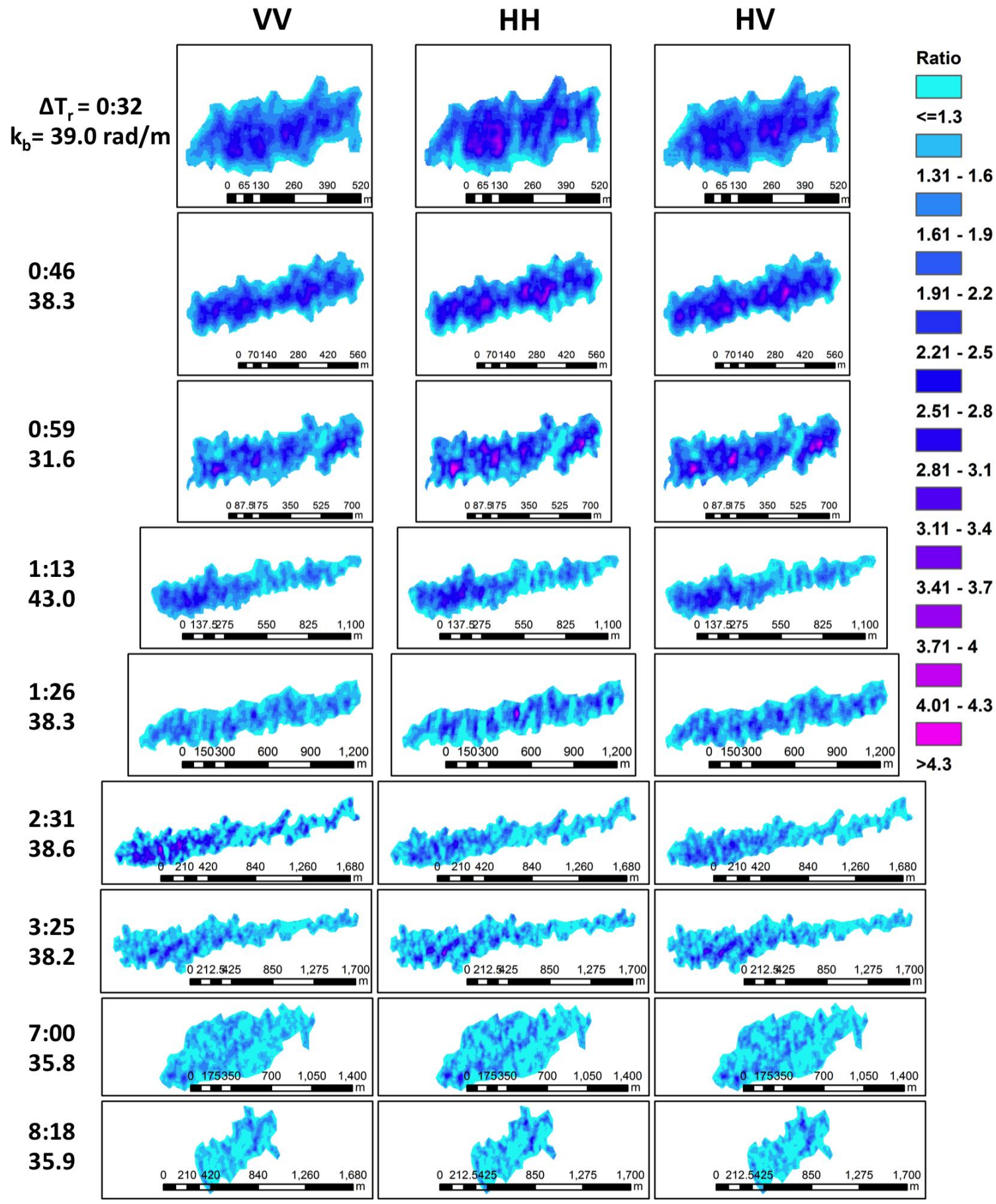

Figure 4. Evolution of the damping ratio for the 40:60 oil-to-water fraction emulsion from 32 minutes following release $\left(\Delta \mathrm{T}_{\mathrm{r}}=0: 32\right)$ to 8 hours, 18 minutes following release $\left(\Delta \mathrm{T}_{\mathrm{r}}=8: 18\right)$. The masks are sized to capture the margins at the interface with clean water and the scale bars show how the slick extent changed with time. The damping ratio is calculated from the VV (left), HH (center) and HV (right) intensities. The Bragg wavenumber $\left(\mathrm{k}_{\mathrm{b}}\right)$ at the slick centroid is indicated for each time step. Note the change in scale for different time steps. 


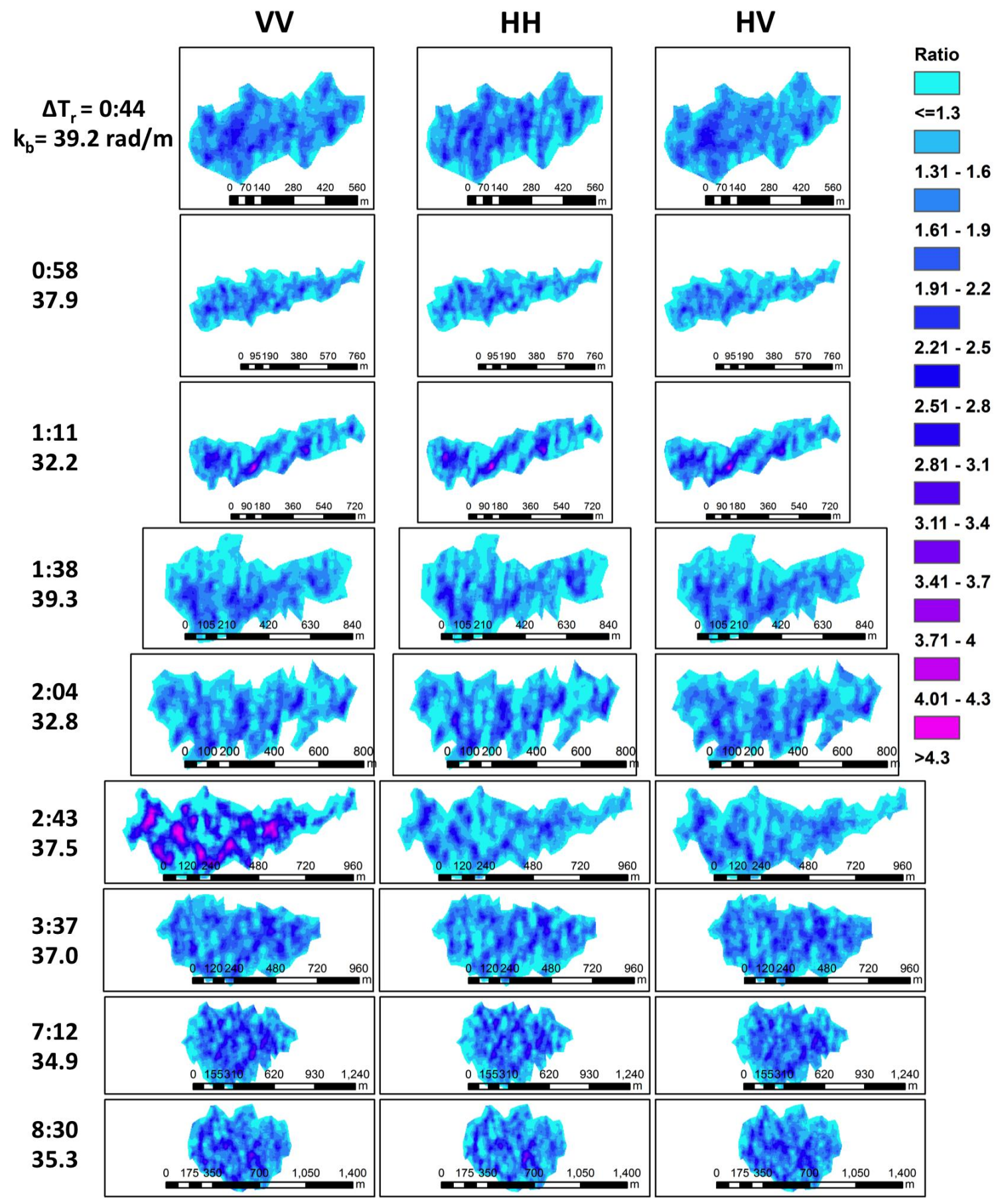

Figure 5. Evolution of the damping ratio for the plant oil (Radiagreen EBO) slick from 44 minutes following release $\left(\Delta \mathrm{T}_{\mathrm{r}}=0: 44\right)$ to 8 hours,30 minutes following release $\left(\Delta \mathrm{T}_{\mathrm{r}}=8: 30\right)$. The masks are sized to capture the margins at the interface with clean water and the scale bars show how the slick extent changed with time. The damping ratio is calculated from the VV (left), HH (center) and HV (right) intensities. The Bragg wavenumber $\left(\mathrm{k}_{\mathrm{b}}\right)$ at the slick centroid is indicated for each time step. Note the change in scale for different time steps. 


\subsection{Temporal evolution of the plant oil's damping ratio}

The evolution of the damping ratio of the plant oil (Figure 5) is different from that of the mineral oil emulsions, although the increase in the $\mathrm{VV}$ damping ratio only is seen in the same scene as for the emulsions, at $\Delta \mathrm{T}_{\mathrm{r}}=2: 43$. This too supports the idea that environmental factors caused the change. Overall, the plant oil displayed little zoning, which is consistent with the substance quickly forming a monomolecular layer. ${ }^{16}$ The initial expansion was not captured for this slick because the first image was acquired at $\Delta \mathrm{T}_{\mathrm{r}}=0: 44$. Although the slick spread initially in the downwind direction, the radar-observable slick rapidly became more circular in shape, losing the tail in the downwind direction. There was little change in the damping ratio between the first $\left(\Delta \mathrm{T}_{\mathrm{r}}=0: 44\right)$ and last $\left(\Delta \mathrm{T}_{\mathrm{r}}=8: 30\right)$ scenes. As for the emulsions, the damping ratios are very similar for all polarizations. The plant oil damping ratio values fall mainly in the range 1.3-1.9 for all polarization channels and all imaging times.

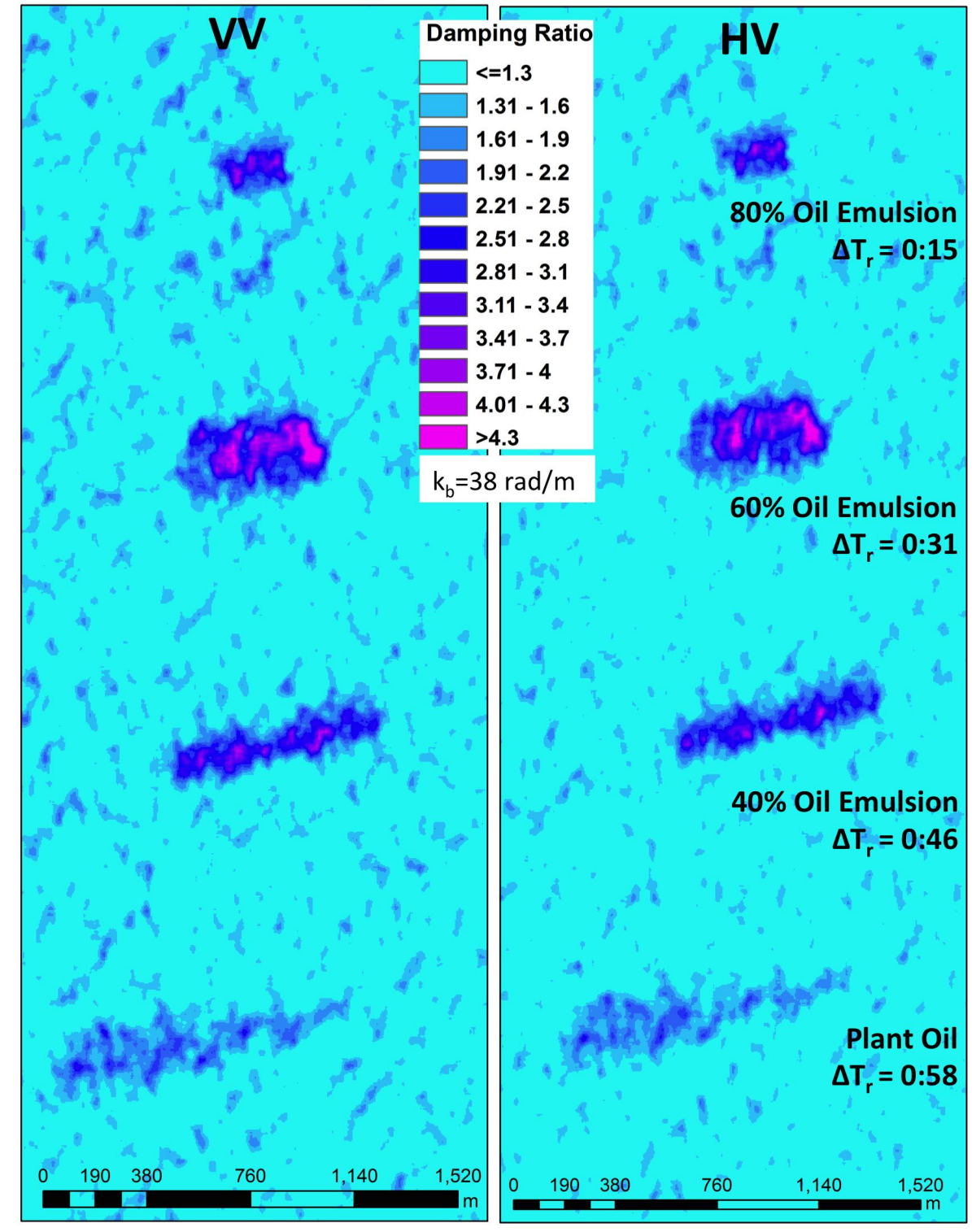

Figure 6. Damping ratio of the sea surface in the area containing the four slicks formed from the releases, with the 80:20 emulsion furthest north, and the 60:40, 40:60, and plant oil slicks to the south. The values calculated from the VV returns are on the left and those calculated from the HV returns are on the right. Time since release $\left(\Delta \mathrm{T}_{\mathrm{r}}\right)$ and Bragg wavenumber $\left(\mathrm{k}_{\mathrm{b}}\right)$ are indicated. The damping ratios are similar for the two polarizations and show zones of higher damping in the interior of the slick. This figure shows the earliest acquired image in which all four slicks were present. 


\subsection{Comparison of emulsion and plant oil slicks}

Figures 6 and 7 show five scenes encompassing all four slicks, starting with the first image containing all four releases (Figure 6) and ending with the last acquired image (Figure 7, lower right). Figure 6 shows both the VV and HV damping ratios, and in this case the VV damping ratio has slightly higher values. The recently released 80:20 oil emulsion has damping ratios near those of the 40:60 oil emulsion, but has not spread nearly as far in the downwind direction. The 60:40 oil emulsion, 30 minutes after release, shows the highest damping ratio observed for any of the slicks and all the imaging times. The damping ratio for all three emulsions is higher in the center of the slick and lower near the edge. This was verified to not be an effect of the smoothing by using different filter lengths, including comparison to no smoothing. At this early time after release, the plant oil slick was much less easily distinguished from the clean sea than the emulsion slicks, and the downwind part of the slick was becoming hard to differentiate. The plant oil slick is readily differentiated from the emulsions by its lack of zoning.

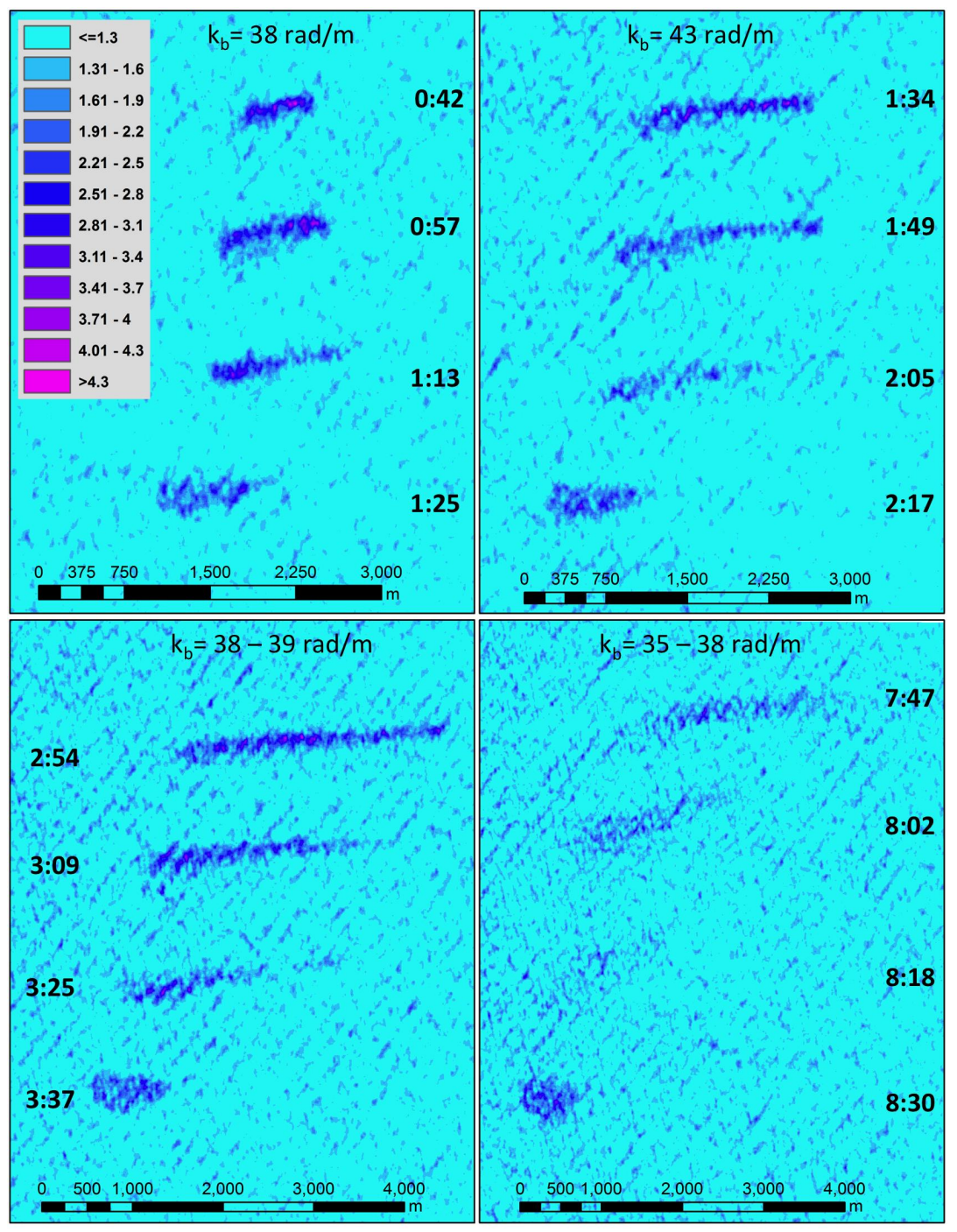

Figure 7. Damping ratio of the sea surface in the area containing the four slicks formed from the releases, with the 80:20 oil emulsion furthest north, and the 60:40,40:60, and plant oil slicks to the south. The values are calculated from the VV returns and show the development of the slicks on the surface in their size, shape, location, and changing damping ratio. Time since release $\left(\Delta \mathrm{T}_{\mathrm{r}}\right)$ and Bragg wavenumber $\left(\mathrm{k}_{\mathrm{b}}\right)$ are indicated. This figure is a continuation of the time series started in Figure 6, and shows that the 80:20 oil emulsion persists the longest of the mineral oil slicks and is spread the furthest to the east (downwind direction). The plant oils slick form a different shape than the mineral oil slicks and has the highest damping ratio of all the slicks after 8:30 on the surface (lower right). 
In the next frame (Figure 7, upper left), acquired 26 minutes later, the 80:20 emulsion has spread significantly in the downwind direction, as have the other emulsion slicks, but the 40:60 oil emulsion now has much smaller damping on the downwind side and little zoning. The plant oil remains less distinct on the downwind side. Fifty-two minutes after the previous image (Figure 7, upper right), the 40:60 emulsion damping is very low, lower than the plant oil, and the 60:40 emulsion has damping values similar to the plant oil. Only the 80:20 emulsion continues to show zoning. Eighty minutes later (Figure 7, lower left), the 40:60 emulsion slick has broken up, the 60:40 emulsion has begun to disappear at the downwind side, and the plant oil slick changed little. The 80:20 emulsion retains some zoning. By the end of the image series (Figure 7, lower right), the 40:60 emulsion is very difficult to detect without prior knowledge of its location, the plant oil retains its previous level of damping, and the 60:40 and 80:20 emulsion slicks are becoming increasingly difficult to distinguish from the clean water.

\section{CONCLUSIONS}

A comparison of the polarization-dependent damping ratio for four different oil slicks, three comprised of mineral oil emulsions and one of a plant oil compound, Radiogreen EBO, was made using a high signal-to-noise ratio L-band airborne SAR, the NASA UAVSAR, to evaluate the capability of low noise, high spatial resolution SAR for identifying zones of thicker oil within relatively small oil slicks $\left(0.2-0.5 \mathrm{~m}^{3}\right.$ release volumes). It was found that all mineral oil slicks initially exhibited zoning, which persisted the longest for the highest oil content emulsion ( $80 \%$ oil by volume), but that zoning was not apparent in the plant oil slick. This was one of the major differences between the emulsion slicks and the plant oil slick. The damping ratios of the emulsions showed significant contrast between the edges and middle of the slick in the first hour following release, consistent with a thicker oil layer in the center and sheen around the edges, much as seen at release (Figure 1). This contrast decreased at a rate that was slowest for the 80:20 oil emulsion and fastest for the 40:60 oil emulsion. The maximum damping ratio was largest for the 60:40 oil emulsion, observed at $\sim 30$ minutes following release. It is possible that more frequent observations could have captured higher damping for the 80:20 emulsion, given that its damping ratio remained high for longer than the 60:40 emulsion. Because the slicks were very thin, the zoning observed is most likely from alteration of the surface wave spectrum with different slick thicknesses, not a change in the dielectric properties. These results show the value of the combination of high spatial resolution and low instrument noise for directing responders to the areas of a slick containing the most oil.

The analysis determined that there are only minor differences between the damping ratios' sensitivity to zoning as measured using the $\mathrm{VV}, \mathrm{HH}$, and $\mathrm{HV}$ modes. The damping ratios for $\mathrm{VV}, \mathrm{HH}$, and $\mathrm{HV}$ polarizations all could be used to identify zoning. For the 80:20 emulsion, the damping ratio from the VV intensity showed the most contrast within the slick of the three polarizations, but environmental conditions rather than oil characteristics could have accounted for the difference. We note that based upon analyses of the statistical properties of the slick returns in aggregate, ${ }^{7,17}$ i.e., averaged across the slicks, the VV intensity damping ratio is slightly better differentiated from clean water than the damping ratios calculated from the other polarizations, followed by $\mathrm{HV}$, then $\mathrm{HH}$ as least sensitive. This suggests that in larger slicks containing greater volumes of oil the VV-intensity would be most sensitive to zoning also, although our slick sample is too small to show this.

The temporal development of the slicks depended strongly upon composition, and one of the more striking results is the contrast between the three mineral oil emulsions and the plant oil in the evolution of the damping ratio with time. The lowest oil emulsion was barely detectable by the end of the observation period, but the slicks of the emulsion with highest oil content and the biogenic simulant remained well delineated throughout the observation period. The spreading and homogenization of the plant oil slick occurred rapidly, and little change in radiometric properties occurred thereafter. The plant oil persisted on the surface with sufficient contrast to be easily identified for longer than any of the emulsions, despite the high wind conditions, much higher than the 7-10 m/s limit where biogenic slicks are found to disappear from the surface. ${ }^{13}$ Previous analysis of the transport of the slicks ${ }^{9}$ showed that the plant oil was entrained in smaller droplets and to greater depth than the emulsions, and served as a reservoir for resurfacing slick material that was protected from wind-induced spreading. This difference in transport and evolution of the damping ratio could be a way to differentiate mineral oil slicks from biogenic slicks, although more work is needed to determine whether biogenic slicks have the same properties as the Radiogreen EBO used in this experiment. 


\section{ACKNOWLEDGEMENTS}

We are grateful to the Norwegian Clean Seas Association for Operating Companies for arranging and executing the NORSE2015 experiment during their annual exercise and for preparation of the mineral oil emulsions that were released. This work was carried out in part at the Jet Propulsion Laboratory, California Institute of Technology, under a contract with the U.S. National Aeronautics and Space Administration (NASA). The Norwegian Centre for Integrated Remote Sensing and Forecasting for Arctic operations (CIRFA) provided financial support through their Research Council of Norway grant \#237906. The UAVSAR data are courtesy of NASA/Jet Propulsion Laboratory. Mention of trade names or commercial products is not an endorsement or recommendation for use by the U.S. Government.

\section{REFERENCES}

[1] Hühnerfuss, H., Alpers, W., Garrett, W. D., Philipp, A. Lange, P. A., and Siegfried, S., "Attenuation of capillary and gravity waves at sea by monomolecular organic surface films," Journal of Geophysical Research: Oceans 88(C14), 9809-9816 (1983).

[2] Singh, K. P., Gray, A. L., Hawkins, R. K., and O'Neil, R. A., "The influence of surface oil on C-and Ku-band ocean backscatter," IEEE Transactions on Geoscience and Remote Sensing 5, 738-744 (1986).

[3] Alpers, W., and Hühnerfuss, H., "Radar signatures of oil films floating on the sea surface and the Marangoni effect." Journal of Geophysical Research 93, 3642-3648 (1988).

[4] Minchew, B., Jones, C. E., and Holt, B., "Polarimetric analysis of backscatter from the Deepwater Horizon oil spill using L-band synthetic aperture radar," IEEE Transactions on Geoscience and Remote Sensing 50(10), 3812-3830 (2012).

[5] Minchew, B., "Determining the mixing of oil and sea water using polarimetric synthetic aperture radar," Geophysical Research Letters 39(16) (2012).

[6] Garcia-Pineda, O., MacDonald, I., Hu, C., Svejkovsky, J., Hess, M., Dukhovskoy, D., and Morey, S. L., "Detection of floating oil anomalies from the Deepwater Horizon oil spill with synthetic aperture radar," Oceanography 26(2), 124-137 (2013).

[7] Skrunes, S., Brekke, C., Jones, C. E., and Holt, B., "A multisensor comparison of experimental oil spills in polarimetric SAR," IEEE Journal of Selected Topics in Applied Earth Observations and Remote Sensing, doi:10.1109/JSTARS.2016.2565063 (2015).

[8] Brekke, C., Jones, C. E., Skrunes, S., Holt, B., Espeseth, M., and Eltoft, T., "Cross-correlation between polarization channels in SAR imagery over oceanographic features," IEEE Geoscience and Remote Sensing Letters, 13(7), 9971001, doi:10.1109/LGRS.2016.2558543 (2015).

[9] Jones, C. E., Dagestad, K.-F., Breivik, Ø., Holt, B., Röhrs, J., Christensen, K. H., Espeseth, M., Brekke, C., Skrunes, S., "Measurement and modeling of oil slick transport," Journal of Geophysical Research: Oceans, in press (2016).

[10] Skrunes, S., Brekke, C., and Eltoft, T., "Characterization of marine surface slicks by Radarsat-2 multi-polarization features," IEEE Transactions on Geoscience and Remote Sensing 52, 5302-5319 (September 2014).

[11] Gade, M., Alpers, W., Wismann, V., and Lange, L., "On the reduction of the radar backscatter by oceanic surface films: Scatterometer measurements and their theoretical interpretation," Remote Sensing of the Environment 66, 5270 (1998).

[12] Valenzuela, G. R., "Theories for the interaction of electromagnetic and ocean waves-A review," Boundary-Layer Meteorol., 13(1-4), 61-85 (1978).

[13] Alpers, W., and Espedal, H.A., "Oils and surfactants," in C. R. Jackson and J. R. Apel (eds) Synthetic Aperture Radar (SAR) Marine User's Manual, NOAA NESDIS Office of Research and Applications, Washington DC, pp. 263-275 (2004).

[14] Wisman, V., Gade, M., Alpers, W., and Hühnerfuss, H., "Radar signatures of marine mineral oil spills measured by an airborne multi-frequency radar," Int. J. Remote Sens., 19(18), 3607-3623 (1998).

[15] Jones, C. E., Minchew, B. Holt, B., and Hensley, S., "Studies of the Deepwater Horizon oil spill with the UAVSAR radar," in Monitoring and Modeling of the Deepwater Horizon Oil Spill: A Record-Breaking Enterprise, edited by Y. Liu, A. MacFadyen, Z.-G. Ji, and R. H. Weisberg, Amer. Geophys. Union, Washington, D.C., 33-50 (2011). 
[16] Fingas, M., and Fieldhouse, B., "Studies on water-in-oil products from crude oils and petroleum products," Marine Pollution Bulletin, 64, 272-283 (2012).

[17] Espeseth, M., Skrunes, S., Brekke, C. Salberg, A.-B., Jones, C. E., and Holt, B., "Oil spill characterization in the hybrid-polarity SAR domain using log-cumulants," this volume.

[18] Hensley, S., Zebker, H. A., Jones, C. E., Michel, T., Muellerschoen, R., and B. Chapman, "First deformation results using the NASA/JPL UAVSAR instrument," in Proceedings of the 2nd Asian-Pacific Conference on Synthetic Aperture Radar, edited by Inst. of Electr. and Electron Eng., Piscataway, N.J., 1051-1055 (2009).

[19] Fore, A. G., Chapman, B. D., Hawkins, B. P., Hensley, S., Jones, C. E., Michel, T. R., and Muellerschoen R. J., "UAVSAR polarimetric calibration," IEEE Transactions on Geoscience and Remote Sensing 53(6), 3481-3491 (2015). 